\title{
Fatigue, Mood, and Sleep, During Intraperitoneal Chemotherapy: A Pilot Case Control Study
}

\author{
Fatiga, Ánimo y Sueño Durante La Quimioterapia \\ Intraperitoneal: un Estudio Caso-Control Piloto
}

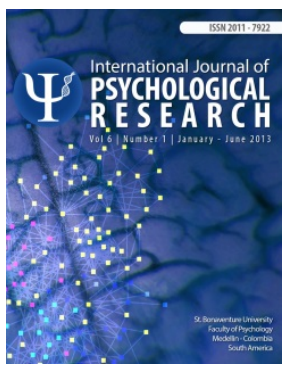

Heather Jim 国, a , Anna Barata ${ }^{\mathrm{b}}$, Robert Wenham ${ }^{\mathrm{a}}$, Paul Jacobsen ${ }^{\mathrm{a}}$

a Moffitt Cancer Center, 12902 Magnolia Drive, Tampa, FL 33612 USA
b Hematology Service, Hospital de la Santa Creu i Sant Pau, Mas Casanova 90, 08004 Barcelona. Universitat Autonoma de Barcelona

\begin{abstract}
The goal of this pilot study was to compare longitudinal changes in fatigue, depressive symptoms, sleep, and activity in women $(n=10)$ undergoing intraperitoneal $(I P)$ versus intravenous (IV) chemotherapy for ovarian cancer. Fatigue and depressive symptoms were assessed via self -report and sleep and activity via wrist actigraphy in the week before and the week after the first infusion. Both groups demonstrated increases in fatigue and depressive symptoms, declines in sleep, reduced daytime activity, and decreased rhythmicity of sleep/activity patterns $(p<.05)$. Effect sizes for within-group comparisons tended to be higher in the IP group (ds $=-.15$ to -8.03) than the IV group (ds $=.12$ to 1.40). Between-group comparisons revealed that IP patients demonstrated trends towards more severe symptoms post-chemotherapy in nearly all outcomes $(p<.10)$. These results suggest that IP patients experience large increases in fatigue, depressive symptoms, and alterations in sleep and activity relative to IV patients.
\end{abstract}

\section{RESUMEN}

El estudio comparó cambios longitudinales en fatiga, síntomas depresivos, sueño y actividad en mujeres con cáncer de ovario $(n=10)$ en tratamiento con quimioterapia intraperitoneal (IP) versus intravenosa (IV). Se evaluó la fatiga y los síntomas depresivos (autoreferidos), y el sueño y la actividad (actigrafia) la semana antes y la posterior a la primera infusión. Ambos grupos refirieron mayor fatiga y síntomas depresivos, disminución del sueño, de la actividad diaria y de los patrones de ritmicidad sueño/actividad $(p<.05)$. Las comparaciones entre el grupo IP (ds $=-.15$ to -8.03 ) y el grupo IV (ds =.12 to 1.40), y las comparaciones entre-grupos revelaron que los síntomas eran más graves en los pacientes IP $(p<.10)$. Los datos obtenidos sugieren que los pacientes IP experimentan mayor incremento en fatiga, síntomas depresivos y alteraciones del sueño y la actividad en comparación con los pacientes IV.

\section{Palabras Clave: \\ Neoplasia ovario, Infusión \\ intraperitoneal, Quimioterapia, Fatiga, Depresión, Sueño.}




\section{INTRODUCTION}

There has been significant interest recently in the use of intraperitoneal (IP) chemotherapy for treatment of ovarian cancer. This interest is attributable to several large randomized clinical trials (Alberts et al., 1996; Armstrong et al., 2006; Markman et al., 2001) and meta-analyses (Elit et al., 2007; Jaaback \& Johnson, 2006) suggesting a survival advantage of 8-16 months of IP over intravenous (IV) cisplatin-based regimens for patients with optimally-debulked Stage III ovarian cancer (Elit et al., 2007). On the basis of this evidence, the National Cancer Institute issued a clinical announcement in 2006 recommending that IP chemotherapy be considered for these patients (Trimble \& Christian, 2008). Nevertheless, there is ongoing debate regarding the use of IP chemotherapy (Armstrong \& Brady, 2006; Gore, Du Bois \& Vergote, 2006) due in part to concerns about toxicity and tolerability (Armstrong \& Brady, 2006; Lesnock et al., 2010).

To date, only one study has examined quality of life in patients receiving IP treatment. Data from the Gynecology Oncology Group GOG-172 trial (Armstrong et al., 2006; Von Gruenigen et al., 2011; Wenzel, Huang, Armstrong, Walker \& Cella, 2007) compared overall quality of life as well as neurotoxicity, abdominal discomfort, and an index of ovarian cancer symptoms in 415 patients receiving IP and IV regimens. After adjusting for age, performance status, and baseline scores, IP patients reported significantly poorer overall quality of life, worse physical and functional well-being, and greater ovarian cancer symptoms at cycle 4 and 3-6 weeks post-treatment; worse abdominal discomfort at cycle 4; and greater neurotoxicity at 3-6 weeks and 12 months post-treatment (Armstrong et al., 2006; Wenzel et al., 2007). These differences are notable and likely underestimate the effects of IP treatment on quality of life, as $40 \%$ of IP patients received two or fewer cycles of IP chemotherapy due to treatment toxicities (Armstrong et al., 2006).

While the GOG-172 trial represents an important first step in describing quality of life in patients treated with IP chemotherapy, additional research is needed to provide a more complete clinical picture of symptoms experienced by IP patients. This research is important because it can help patients make informed treatment decisions; both the Gynecology Oncology Group (Alberts et al., 2006), and the American College of Obstetricians and Gynecologists (2008) have concluded that the choice to receive IP treatment should ultimately be made by informed patients. The aim of this pilot study was to examine changes in fatigue, depressive symptoms, sleep, and activity in ovarian cancer patients undergoing IP versus IV chemotherapy. These four symptoms were selected because they tend to be particularly disruptive and troubling to ovarian cancer patients (Anderson \& Hacker, 2008; Havrilesky et al., 2009). Participants were assessed the week before and the week after the first treatment because symptoms may be most acute during this period. It was hypothesized that IP patients would show greater increases in symptoms (i.e., fatigue, depression, disturbances in sleep and activity) over time and more severe post-treatment symptoms than IV patients.

\section{METHODS}

Table 1. Actigraphic Measurement of Sleep and Activity

\begin{tabular}{|c|c|c|}
\hline Construct & Variable & $\begin{array}{c}\text { Direction } \\
\text { indicating better } \\
\text { functioning }\end{array}$ \\
\hline \multirow[t]{6}{*}{$\begin{array}{l}\text { Sleep } \\
\text { quality }\end{array}$} & $\begin{array}{l}\text { Mean duration of nighttime rest } \\
\text { periods }\end{array}$ & -- \\
\hline & $\begin{array}{l}\text { Mean percentage of nighttime } \\
\text { rest periods spent sleeping }\end{array}$ & Higher \\
\hline & $\begin{array}{l}\text { Mean number of times the } \\
\text { participant woke up during the } \\
\text { nighttime rest period }\end{array}$ & Lower \\
\hline & Mean time until sleep onset & Lower \\
\hline & $\begin{array}{l}\text { Mean time awake after sleep } \\
\text { onset (i.e., WASO) }\end{array}$ & Lower \\
\hline & $\begin{array}{l}\text { Mean percent of daytime non- } \\
\text { rest periods spent sleeping }\end{array}$ & Lower \\
\hline \multirow[t]{2}{*}{ Activity } & $\begin{array}{l}\text { Mean activity per minute during } \\
\text { nighttime rest periods }\end{array}$ & Lower \\
\hline & $\begin{array}{l}\text { Mean activity per minute during } \\
\text { daytime non-rest periods }\end{array}$ & Higher \\
\hline \multirow{2}{*}{$\begin{array}{l}\text { Sleep/acti } \\
\text { vity } \\
\text { patterns }\end{array}$} & $\begin{array}{l}\text { Mesor (i.e., overall mean } \\
\text { activity level for } 24 \text {-hour period) }\end{array}$ & Higher \\
\hline & $\begin{array}{l}\text { Mean dichotomy index (i.e., } \\
\text { activity during daytime non-rest } \\
\text { periods divided by activity } \\
\text { during nighttime rest periods) }\end{array}$ & Higher \\
\hline
\end{tabular}

\subsection{Participant Selection and Recruitment}

Following Institutional Review Board approval, participants were recruited between January, 2007 and April, 2008. Patients were eligible to participate if they: 1) were at least 18 years of age; 2) were diagnosed with ovarian cancer; 3) were scheduled to undergo IP or IV chemotherapy at Moffitt Cancer Center (Tampa, Florida; United States) had not previously undergone chemotherapy or radiotherapy in the three months prior to study 
recruitment; 5) had no documented or observable psychiatric or neurological conditions that would interfere with study participation; 6) were capable of reading and speaking English; and 7) were able to provide informed consent.

\subsection{Procedures}

Participants were recruited and informed consent obtained during a regularly scheduled outpatient appointment with their medical oncologist at Moffitt Cancer Center. Participants began sleep/activity monitoring with wrist actigraphy a mean of 6.7 days (range 4-8) before the first treatment and wore actigraphs continuously a mean of 6.1 (range 47) after the first treatment. Participants also completed self-report measures of fatigue and depressive symptoms at their first treatment and one week later.

\subsection{Measures}

Demographic and clinical variables. Age, race, ethnicity, marital status, annual household income, and education were assessed in all participants through self-report. Data regarding time since diagnosis, disease stage, disease recurrence, and current chemotherapy regimen were collected via medical chart review.

Fatigue. The Fatigue Symptom Inventory (FSI) (Hann et al., 1998) is a 14-item measure that assesses the frequency and severity of fatigue and its perceived disruptiveness in the past week. Analyses were conducted using ratings of most fatigue in the past week ( $0=$ not at all fatigued, $10=$ as fatigued as I could be). Previous research has demonstrated the reliability and validity of the FSI in cancer patients (Hann et al., 1998).

Depressive symptoms. The 20-item Center for Epidemiological Studies of Depression Scale (CES-D) (Radloff, 1977) scale identifies current symptoms of depression in the past week. Scores range from 0 to 60 , with higher scores indicating greater depressive symptoms. Previous research has demonstrated the reliability and validity of the CES-D in individuals with cancer (Hann, Winter \& Jacobsen, 1999).

Sleep, activity, and sleep/activity patterns. Sleep, activity, and sleep/activity patterns were assessed via actigraphic monitoring using the Actiwatch $®$-Score (MiniMitter, Bend, OR). Actigraphy is a reliable and valid way of objectively measuring sleep and physical activity (Patterson et al., 1993; Webster, Kripke, Messin, Mullaney \&
Wyborney, 1982) which demonstrates expected relationships with clinically-relevant outcomes (e.g., quality of life) in cancer patients (Mormont \& Waterhouse, 2002). In accordance with the recommendations of Berger et al. (2008), sleep, activity, and sleep/activity patterns were calculated using actigraphy data in combination with patients' daily reports of bedtime and rising time using Actiware 5 software. Actigraphy variables are defined in Table 1.

\section{RESULTS}

Table 2. Sociodemographic and Clinical Characteristics of the Sample.

\begin{tabular}{|c|c|c|c|}
\hline & IV $(n=5)$ & IP $(n=5)$ & Statistic \\
\hline Age - M(SD) & $\begin{array}{l}58.17 \\
(15.79)\end{array}$ & $\begin{array}{l}46.61 \\
(8.58)\end{array}$ & $W=35$ \\
\hline $\begin{array}{l}\text { Ethnicity (\% non- } \\
\text { Hispanic) }\end{array}$ & $100 \%$ & $80 \%$ & $x^{2}=1.11$ \\
\hline Race (\% Caucasian) & $80 \%$ & $80 \%$ & $x^{2}=0$ \\
\hline $\begin{array}{l}\text { Marital status (\% } \\
\text { married) }\end{array}$ & $80 \%$ & $100 \%$ & $x^{2}=1.11$ \\
\hline $\begin{array}{l}\text { Education (\% college } \\
\text { grad) }\end{array}$ & $40 \%$ & $40 \%$ & $x^{2}=.09$ \\
\hline $\begin{array}{l}\text { Annual household } \\
\text { income }(\% \geq \$ 40 k)\end{array}$ & $33 \%$ & $66 \%$ & $x^{2}=.66$ \\
\hline $\begin{array}{l}\text { Months since initial } \\
\text { diagnosis }\end{array}$ & $\begin{array}{l}7.32 \\
(15.36)\end{array}$ & $4.68(6.21)$ & $W=22$ \\
\hline Disease stage & & & $x^{2}=3.14$ \\
\hline Stage I & $20 \%$ & $0(0 \%)$ & \\
\hline Stage II & $20 \%$ & $0(0 \%)$ & \\
\hline Stage III & $60 \%$ & $80 \%$ & \\
\hline Stage IV & $0 \%$ & $20 \%$ & \\
\hline $\begin{array}{l}\text { Recurrent disease } \\
\text { (\% yes) }\end{array}$ & $10 \%$ & $0 \%$ & $x^{2}=1.11$ \\
\hline Chemotherapy regimen & & & $\begin{array}{l}x^{2}= \\
10.00^{\star *}\end{array}$ \\
\hline $\begin{array}{l}\text { Carboplatin/ } \\
\text { paclitaxel }\end{array}$ & $100 \%$ & $0 \%$ & \\
\hline Cisplatin/ paclitaxel & $0 \%$ & $100 \%$ & \\
\hline
\end{tabular}

Note: Wilcoxon-Mann-Whitney and Fisher exact tests were used. Not all participants reported education or household income data. ${ }^{* \star} p<.01$

Wilcoxon-Mann-Whitney and Fisher exact tests were used to compare sociodemographic and clinical characteristics between IP and IV groups (see Table 2). Within- and between-group 
comparisons in symptoms were conducted using Wilcoxon signed rank tests and Wilcoxon-MannWhitney tests, respectively. All analyses were conducted using SAS 9.2. To examine the clinical significance of group differences in symptom change and symptoms at Time 2, we also calculated effect sizes by subtracting the mean at the first assessment from the mean of the second assessment, then dividing by the pooled standard deviation. For the sake of comparison, Cohen defined small, medium, and large effect sizes as .2, .5, and .8, respectively (Cohen, 1988). An effect size of .5 or higher is considered clinically significant (Frost et al., 2007).

Table 3 - Means, Standard Deviations, and Within- and Between-Group Effect Sizes of Fatigue, Depression, and Sleep/Activity Patterns

\begin{tabular}{|c|c|c|c|c|c|c|c|}
\hline & \multicolumn{3}{|c|}{ IV (n=5) } & \multicolumn{3}{|c|}{ IP (n=5) } & \multirow{2}{*}{$\begin{array}{l}\text { Time } 2 \\
\text { IV vs. IP } \\
d\end{array}$} \\
\hline & Time 1 & Time 2 & $d$ & Time 1 & Time 2 & $D$ & \\
\hline Fatigue (FSI) & $3.20(3.27)$ & $7.20(4.21)$ & 1.22 & $3.00(3.08)$ & $7.60(2.51)$ & 1.49 & .12 \\
\hline $\begin{array}{l}\text { Depressive symptoms (CES- } \\
\text { D) }\end{array}$ & 11.00 (9.97) & $18.40(8.14)$ & .74 & $8.0(6.35)$ & $25.46(12.33)$ & $2.66^{\dagger}$ & .69 \\
\hline $\begin{array}{l}\text { Duration of nighttime rest } \\
\text { periods (min) }\end{array}$ & 484.51 (71.18) & $572.56(100.63)$ & 1.24 & 512.67 (31.82) & $565.49(69.83)$ & $1.66^{\dagger}$ & -.08 \\
\hline $\begin{array}{l}\text { Activity during nighttime rest } \\
\text { periods (activity counts) }\end{array}$ & $38.33(16.02)$ & $45.65(22.80)$ & .46 & 36.87 (3.01) & 46.00 (1.69) & $3.03^{\dagger}$ & .03 \\
\hline $\begin{array}{l}\text { Percent sleep during } \\
\text { nighttime rest periods }\end{array}$ & 81.65 (3.24) & $77.62(7.45)$ & 1.24 & $77.76(.97)$ & $75.16(2.62)$ & $2.68^{\dagger}$ & -.49 \\
\hline $\begin{array}{l}\text { Wake bouts during nighttime } \\
\text { rest periods (number) }\end{array}$ & $24.64(11.18)$ & $28.11(10.37)$ & .31 & $33.65(4.54)$ & $30.62(8.02)$ & .67 & .27 \\
\hline $\begin{array}{l}\text { Sleep onset during nighttime } \\
\text { rest periods (minutes) }\end{array}$ & $22.93(14.36)$ & 24.62 (9.51) & .12 & $16.48(10.76)$ & $14.82(7.47)$ & .15 & -1.15 \\
\hline $\begin{array}{l}\text { Wake after sleep onset } \\
\text { during nighttime rest periods } \\
\text { (minutes) }\end{array}$ & $59.50(14.07)$ & $95.89(42.97)$ & 2.59 & $84.19(21.16)$ & $109.13(28.92)$ & 1.17 & .37 \\
\hline $\begin{array}{l}\text { Activity during daytime } \\
\text { (activity counts) }\end{array}$ & 239.52 (85.96) & 218.12 (68.77) & .25 & $\begin{array}{l}368.99 \\
(108.48)\end{array}$ & $181.79(24.64)$ & $1.73^{\dagger}$ & -.78 \\
\hline Percent sleep during daytime & $17.34(7.87)$ & $25.09(12.17)$ & .98 & $8.18(2.64)$ & $29.39(8.74)$ & $8.03^{\dagger}$ & .41 \\
\hline Mesor & $204.50(68.34)$ & $146.10(47.90)$ & $.85^{\dagger}$ & 266.49 (93.66) & 141.79 (15.09) & $1.33^{\dagger}$ & -.14 \\
\hline Dichotomy index $(\mathrm{I} / \mathrm{O})$ & $.16(.05)$ & $.23(.14)$ & 1.40 & $.11(.03)$ & $.26(.05)$ & $5.00^{\dagger}$ & .32 \\
\hline
\end{tabular}

Note: No comparisons were statistically significant at $p<.05$.

${ }^{\dagger} p<.10$ using Wilcoxon Signed Rank Tests

As shown in Table 3, both IV and IP patients demonstrated increases in fatigue and depressive symptoms as well as declines in almost all indices of sleep. IP and IV patients also demonstrated alterations over time in activity, including decreased activity during daytime periods and greater activity during nighttime rest periods, as well as worse rhythmicity of sleep and activity. Effect sizes for within-group comparisons tended to be higher in the IP group (ds = .15 to 8.03) than the IV group (ds = .12 to 1.40 ), with the exception of wake after sleep onset (WASO). Between-group comparisons at Time 2 revealed that the IP group demonstrated more severe symptoms in all indices measured with the exception of duration of rest periods and sleep onset. Among symptoms more severe for IP patients, activity during nighttime rest periods $(d=.78)$ and depressive symptoms $(d=.69)$ showed the greatest differences. No within- or between-group comparisons reached statistical significance (i.e., $p<$ $.05)$, as would be expected given the small sample size . However, trends ( $p s<.10)$ were observed for within-group changes in mesor (i.e., average activity values over a 24 hour period) in IV patients and for the majority of within-group changes in IP patients. Regarding clinical significance, both IV and IP patients at Time 2 reported mean FSI and CES-D scores above clinical threshold of 7 for severe fatigue 
on the FSI (Berger et al., 2009) and 16 for clinically significant depressive symptomatology on the CESD (Andresen, Malmgrem, Carter \& Patrick, 1994). Moreover, IP and IV patients reported increases in nighttime rest by 53 and 88 minutes and increases in wake after sleep onset by 25 and 36 minutes, respectively.

\section{DISCUSSION}

The present pilot study compared within- and between-group differences in fatigue, depressive symptoms, sleep, and activity in women receiving IP versus IV chemotherapy for ovarian cancer. Both IP and IV patients displayed increases in fatigue and depressive symptoms and declines in sleep in the week after their first chemotherapy infusion as compared to before. These declines have been welldocumented in IV patients (Roscoe et al., 2002), but to our knowledge this is the first study to examine these symptoms in IP patients. The magnitude of these changes was generally large, with effect sizes of .8 standard deviations or above in seven of the twelve outcomes measured in IV patients and ten of twelve outcomes in IP patients. Particularly notable in IP patients were changes of several standard deviations in fatigue, depressive symptoms, activity during rest, activity during non-rest periods, sleep during non-rest periods, and disrupted sleep/activity patterns. These data help to document the subjective symptoms and objective behavioral changes that women experience as they struggle to cope with IP as compared to IV treatment.

Strengths of the current study include a longitudinal design as well as assessment with actigraphy and well-validated measures of depressive symptoms and fatigue. Nevertheless, the study is not without its limitations. First, patients were not randomized to receive IP versus IV chemotherapy, so attribution of group differences in symptoms to treatment must be considered with caution. Patients showed group differences in age, stage, and annual household income. Although nonsignificant, these differences may have affected between-group comparisons. Second, the study lacked long-term follow-up assessments to document how symptoms changed as treatments progressed and then ceased. Third, the chemotherapy regimens were different between groups, with the IV group receiving carboplatin/paclitaxel and the IP group receiving cisplatin/paclitaxel, which may have contributed to group differences. Fourth, the sample size was small. The small sample size may result in less reliable estimates of group means and standard deviations and necessitated less-powerful nonparametric statistical tests, which may explain a lack of statistically significant differences despite large effect sizes. The sample size in the current study was a function of the small number of patients receiving IP chemotherapy at Moffitt Cancer Center as well as an a priori decision to recruit a comparable number of IP and IV patients.

The small number of IP patients reflects several possible barriers to widespread adoption of IP treatment, despite the fact that it is currently the standard of care for some ovarian cancer patients (Trimble \& Christian, 2008). First, relatively small numbers of patients meet criteria for its use. Second, there is significant debate in the field of gynecologic oncology regarding whether the survival benefits of IP treatment outweigh the risks of longterm toxicity. Finally, if given the choice, patients themselves may be reluctant to undergo IP treatment in light of greater toxicity and increased treatment burden (i.e., inpatient versus outpatient administration after the first infusion).

\section{CONCLUSIONS}

Debate regarding the use of IP chemotherapy for ovarian cancer will only be resolved through additional research. To this end, the current pilot study provides an initial longitudinal comparison of four common and distressing symptoms: changes in fatigue, depressive symptoms, sleep, and activity in patients receiving platinum-based IP or IV chemotherapy. Future research should build upon the pilot data presented here to conduct larger, well-powered follow-up studies of these symptoms. Research of this kind has the potential to greatly enhance informed decision-making among women considering IP versus IV chemotherapy for ovarian cancer.

\section{REFERENCES}

Alberts, D. S., Liu, P. Y., Hannigan, E .V., O'Toole, R., Williams, S. D., Young, J. A,....Malviya,V. K. (1996). Intraperitoneal cisplatin plus intraneous cyclophosphamide for stage III ovarian cancer. The New England Journal of Medicine, 335(26), 1950-1955.

Alberts, D. S., Markman, M., Muggia, F., Ozols, R. F., Eldermire, E., Bookman, M. A. ... Trimble E. (2006). Proceedings of a GOG workshop on intraperitoneal therapy for ovarian cancer. Gynecologic Oncology, 103(3), 783-792.

Anderson, N. J. \& Hacker E. D. (2008). Fatigue in women receiving intraperitoneal chemotherapy for ovarian cancer: a review of contributing factors. Clinical Journal of Oncology Nursing, 12(3), 445-454. 
Andresen, E. M., Malmgren, J. A., Carter, W. B. \& Patrick, D. L. (1994). Screening for depression in well older adults: evaluation of a short form of the CES-D (Center for Epidemiologic Studies Depression Scale). American Journal of Preventive Medicine, 10(2), 77-84.

Armstrong, D. K., Bundy, B., Wenzel, L., Huang, $H$. Q., Baergen, R., Lele, S. ... Gynecologic Oncology Group. (2006). Intraperitoneal cisplatin and paclitaxel in ovarian cancer. The New England Journal of Medicine, 354(1), 34-43.

Armstrong, D. K. \& Brady M. F. (2006). Intraperitoneal therapy for ovarian cancer: a treatment ready for prime time. Journal of Clinical Oncology, 24(28), 4531-4533.

Berger, A. M., Wielgus, K. K., Young-McCaughan, S., Fischer, P., Farr, L. \& Lee, K. A. (2008). Methodological challenges when using actigraphy in research. Journal of Pain and Symptom Management, 36(2), 191-199.

Berger, A. M., Abernethy, A., Atkinson, A., Barsevick, A., Breitbart, W. S., Cella, D. ... Wagner, L. L. (2009). NCCN Clinical Practice Guidelines in Oncology: Cancer-Related Fatigue Available from: http://www.nccn.org/professionals/physician_ gls/f_guidelines.asp.

Cohen, J. (1988) Statistical power for the behavioral sciences. Hillsdale, NJ: Lawrence Erlbaum Associates.

Elit, L., Oliver, T. K., Covens, A., Kwon, J., Fung, M. F., Hirte, H. W. \& Oza, A. M. (2007). Intraperitoneal chemotherapy in the first-line treatment of women with stage III epithelial ovarian cancer: a systematic review with metaanalyses. Cancer, 109(4), 692-702.

Frost, M. H., Bonomi, A. E., Cappelleri, J. C., Schünemann, H. J., Moynihan, T. J., Aaronson, N. K., \& Clinical Significance Consensus Meeting Group. (2007). Applying quality-of-life data formally and systematically into clinical practice. Mayo Clinic Proceedings, 82(10), 1214-1228.

Gore, M., Du Bois, A. \& Vergote, I. (2006). Intraperitoneal chemotherapy in ovarian cancer remains experimental. Journal of Clinical Oncology, 24(28), 4528-4530.

Hann, D. M., Jacobsen, P. B., Azzarello, L. M., Martin, S. C., Curran, S. L., Fields, K. K. ... Lyman G. (1998). Measurement of fatigue in cancer patients: development and validation of the Fatigue Symptom Inventory. Quality of Life Research, 7(4) 301-310.

Hann, D., Winter, K. and Jacobsen, P. B. (1999). Measurement of depressive symptoms in cancer patients: evaluation of the Center for Epidemiological Studies Depression Scale (CES-D). Journal of Psychosomatic Research, 46(5), 437-443.

Havrilesky, L. J., Broadwater, G., Davis, D. M., Nolte, K. C., Barnett, J. C., Myers, E. R. \& Kulasingam S. (2009). Determination of quality of life-related utilities for health states relevant to ovarian cancer diagnosis and treatment. Gynecologic Oncology, 113(2), 216-220.

Jaaback, K. \& Johnson N. (2006). Intraperitoneal chemotherapy for the initial management of primary epithelial ovarian cancer. Cochrane Database Systematic Reviews CD005340. doi: 10.1002/14651858

Lesnock, J. L., Richard, S. D., Zorn, K. K., Krivak, T. C., Beriwal, S., Sukumvanich, P. ... Edwards R. P. (2010). Completion of intraperitoneal chemotherapy in advanced ovarian cancer and catheter-related complications. Gynecologic Oncology, 116(3), 345-350.

Markman, M., Bundy, B. N., Alberts, D. S., Fowler, J. M., Clark-Pearson, D. L., Carson, L. F. ... Sieckel, J. (2001). Phase III trial of standarddose intravenous cisplatin plus paclitaxel versus moderately high-dose carboplatin followed by intravenous paclitaxel and intraperitoneal cisplatin in small-volume stage III ovarian carcinoma: an intergroup study of the Gynecologic Oncology Group, Southwestern Oncology Group, and Eastern Cooperative Oncology Group. Journal of Clinical Oncology, 19(4), 1001-1007.

Mormont, M. C. \& Waterhouse, J. (2002). Contribution of the rest-activity circadian rhythm to quality of life in cancer patients. Chronobiology International, 19(1), 313-323.

Patterson, S. M., Krantz, D. S., Montgomery, L. C., Deuster, P. A., Hedges, S. A. \& Nebel, L. E. (1993). Automated physical activity monitoring: Validation and comparison with physiological and self-report measures. Psychophysiology, 30(3), 296-305.

Radloff, L. S. (1977). The CES-D scale: A self-report depression scale for research in the general population. Applied Psychological Measurement, 1, 385-401.

Roscoe, J. A., Morrow, G. R., Hickok, J. T., Bushunow, P., Matteson, S., Rakita, D. \& Andrews, P. L. (2002). Temporal interrelationships among fatigue, circadian rhythm and depression in breast cancer patients undergoing chemotherapy treatment. Supportive Care in Cancer, 10(4), 329-336. 
Trimble, E. L. \& Christian, M. C. (2008). National Cancer Institute-United States strategy regarding intraperitoneal chemotherapy for ovarian cancer. International Journal of Gynecologic Cancer, 1, 26-28.

Webster, J. B., Kripke, D. F., Messin, S., Mullaney, D. J. \& Wyborney, G. (1982). An activitybased sleep monitor system for ambulatory use. Sleep, 5(4), 389-399.

Wenzel, L. B., Huang, H. Q., Armstrong, D. K., Walker, J. L. \& Cella, D. (2007). Healthrelated quality of life during and after intraperitoneal versus intravenous chemotherapy for optimally debulked ovarian cancer: a Gynecologic Oncology Group Study. Journal of Clinical Oncology, 25(4), 437-443.

Von Gruenigen, V. E., Huang, H. Q., Gil, K. M., Frasure, H. E., Armstrong, D. K. \& Wenzel, L. B. (2012). Gynecologic Oncology, 124(3), 379-82. doi: 10.1016/j.ygyno.2011.11.032 